\title{
Drought Analysis of Bitlis River Baykan Station with Streamflow Drought Index (SDI) Method
}

${ }^{1 *}$ Mehmet ÖZCAN, ${ }^{1}$ Veysel GÜMÜŞ, ${ }^{1}$ Oğuz ŞİMŞEK and ${ }^{1}$ Mehmet ŞEKER

${ }^{1}$ Faculty of Engineering, Department of Civil Engineering, Harran University, Turkey

\begin{abstract}
In this study, temporal hydrological drought of Baykan Station E26A010 in the Tigris Basin is calculated using monthly average flow data between 1955 and 2016. In order to determine the hydrological drought, the Stremflow Drought Index (SDI) method is used. Drought indices are evaluated by taking into consideration the time scales of 1 , 3, 6 and 12 months. As a result of the study, according to the monthly data, the highest dry period is realized in June with $65 \%$ and the lowest dry period is in March with $48 \%$.
\end{abstract}

Key words: Tigris basin, Streamflow Drought Index, Drought, Baykan station

\section{Bitlis Çayı Baykan İstasyonunun Akım Kuraklık İndeksi (AKi) Yöntemiyle Kuraklık Analizi}

\section{Özet}

Bu çalışmada Dicle Havzasında bulunan E26A010 numaralı Baykan İstasyonunun 1955 ile 2016 yılları arasındaki aylık ortalama akım verileri kullanılarak zamansal hidrolojik kuraklığı hesaplanmıştır. Hidrolojik kuraklığın belirlenebilmesi için Akım Kuraklık İndeksi (AKİ) yöntemi kullanılmıştır. 1, 3, 6 ve 12 aylık zaman ölçeklerini dikkate alarak kuraklık indisleri değerlendirilmiştir. Çalışma sonucunda, aylık akım verilerine göre en yüksek kurak dönem \%65 ile haziran ayında gerçekleşirken, en düşük kurak dönem ise \%48 ile mart ayında meydana gelmiştir.

Anahtar kelimeler: Dicle havzası, Akım Kuraklık İndeksi, Kuraklık, Baykan istasyonu

\section{Giriş (Introduction)}

Hidrolojik dengenin bozulmasına, bunun yanında arazi ve su kaynaklarının olumsuz etkilenmesine sebep olan kuraklık, yağışın kaydedilen normal seviyelerinin altına düşmesi olarak tanımlanabilir. Kuraklığın başlangıcının ve bitişinin belirsiz olması, kümülatif artması, aynı anda birden fazla kaynağa etkisi ve ekonomik etkisinin büyük olması, kuraklığın en önemli özelliklerinden olup etkilerinin de irdelenmesini olası zararların önlenebilmesi açısından önem arz etmektedir.

Kuraklığın literatürde tanımlanan birçok çeşidi olmakla beraber; meteorolojik kuraklık, tarımsal kuraklık ve hidrolojik kuraklık olmaz üzere üç belirgin tipi vardır. Kuraklık, yağışın doğrudan etkilediği ve en önemli parametre olarak kabul edildiği meteorolojik kuraklık olarak başlar ve devamında hidrolojik ve tarımsal kuraklığa neden olur [1]. Yağış eksikliği durumunda meteorolojik kuraklık, yüzeysel ya da yeraltı suyundaki eksiklik durumunda ise hidrolojik kuraklık meydana gelir. Tarımsal kuraklık ise yağış, yerüstü ve yeraltı su eksikliğinin tarımsal üretkenliği kısaltması durumu ile ifade edilebilir. Kuraklık, tarımsal üretimin azalmasına ve buna bağlı olarak insanların ekonomik dengelerinin bozulmasına, işsizliğe ve hatta göçe neden olabilmektedir. Yüzeysel sular ile yeraltı sularının azalması da enerji üretiminin azalmasına ve buna bağlı olarak sosyo-ekonomik yapının bozulmasına sebebiyet verebilmektedir. Tüm bu olumsuz sonuçlar yaşam üzerinde doğrudan etkili olduğundan kuraklığın etkilerinin en aza indirgenebilmesi için bölgesel bazda geçmiş veriler kullanılarak yapılan kuraklık analizleri oldukça önem arz etmektedir [1].

Kuraklık indisleri, kuraklığın izlenmesinin en temel yoludur. Bu sayede kuraklığın nicel olarak süre ve

*Corresponding author: Address: Faculty of Engineering, Department of Civil Engineering Harran University, 63050, Şanliurfa TURKEY. E-mail address: gumus@ harran.edu.tr, Phone: +904143183000/1274 
şiddetinin belirlenmesi mümkün olabilmektedir. Meteorolojik ve hidrolojik kuraklığın belirlenebilmesi için literatürde birçok yöntem önerilmektedir. Meteorolojik kuraklık için, Palmer Kuraklık Şiddeti İndeksi (Palmer Drought Severity Index -PDSI) [2], Keşif Kuraklık İndeksi-KKİ (The Reconnaissance Drought Index-RDI) [3] yöntemleri kullanılmaktadır. Bu yöntemler ise girdi parametresi olarak tarihsel sicaklık ve yağış verilerini kullanmaktadırlar. Bunun yanında, sadece yağışa bağlı kuraklık indeksi hesaplayan Standartlaştırılmış Yağış İndeksi-SYİ (The Standardized Precipitation Index-SPI) [4] yöntemi ise literatürde kuraklığın belirlenmesi amacıyla özellikle meteorolojik veri olarak sadece yağışın bulunduğu durumlarda siklıkla kullanılmaktadır [5-7].

Hidrolojik kuraklığın belirlenmesinde ise Yüzey Suyu İhtiyaç İndeksi (The Surface Water Supply IndexSWSI) yağışın yanı sıra topoğrafik değişiklikleri, akış ve kar birikimini de dikkate alır [8]. SWSI'ye benzer olarak, Kuraklık İyileştirme Yöntemi (The Reclamation Drought Index-RCDI) yukarıda bahsedilen parametrelerin yanına ayrıca sıcaklık parametresini de kullanarak havza bazında kuraklığın değerlendirilmesine imkân tanımaktadır [9]. Nalbantis [10] tarafından önerilen Akım Kuraklık İndeksi-AKİ ise sadece aylık ortalama akım değerlerini kullanır ve diğer hidrolojik kuraklık izleme yöntemlerinden farklı olarak çok daha az veri girdisi ihtiyacı vardır. Son yıllarda AKI kullanılarak hidrolojik kuraklığın izlenmesinde Türkiye'de ve Dünya'da yapılan çeşitli çalışmalar bulunmaktadır $[1,11,12,13]$.

Bu çalışmada yalnızca aylık ortalama akım verileri kullanılarak hidrolojik kuraklık indisi hesaplayan akım kuraklık indeksi (AKİ) yöntemiyle Türkiye'nin su potansiyeli açısından oldukça önemli olan Dicle Havzasında bulunan ve Bitlis Çayı üzerinde yer alan E26A010 numaralı 'Baykan'” istasyonunun hidrolojik kuraklığı değerlendirilmiştir.

\section{Materyal ve Yöntem (Materials and Method)}

\section{1 Çalışma Alanı (Study Area)}

Dicle Nehri, Türkiye'de doğup birçok kolu olan ve Irak topraklarına geçip orada Fırat Nehri birleşerek Şattülarap’ta Basra Körfezi'ne dökülür. Nehir ana kaynaklarını, Doğu Anadolu Bölgesi dağlarından ve dipten sızma yoluyla Elâzığ yakınlarındaki Hazar gölünden alır. Toplam uzunluğu 1900 km civarında olup ülkemiz topraklarındaki uzunluğu yaklaşık olarak $523 \mathrm{~km}$ iken yaklaşık olarak 1377 km'lik uzunluğu ise Irak sınırları içinde bulunmaktadır. Bu çalışmada birden fazla akarsu ile birleşerek Dicle Nehrine akmakta olan ve Şekil 1'de gösterilen Bitlis Çayı üzerindeki E26A010 numaralı "Baykan" istasyonuna ait aylık ortalama akım verileri kuraklığın belirlenmesinde kullanılmıştır. 


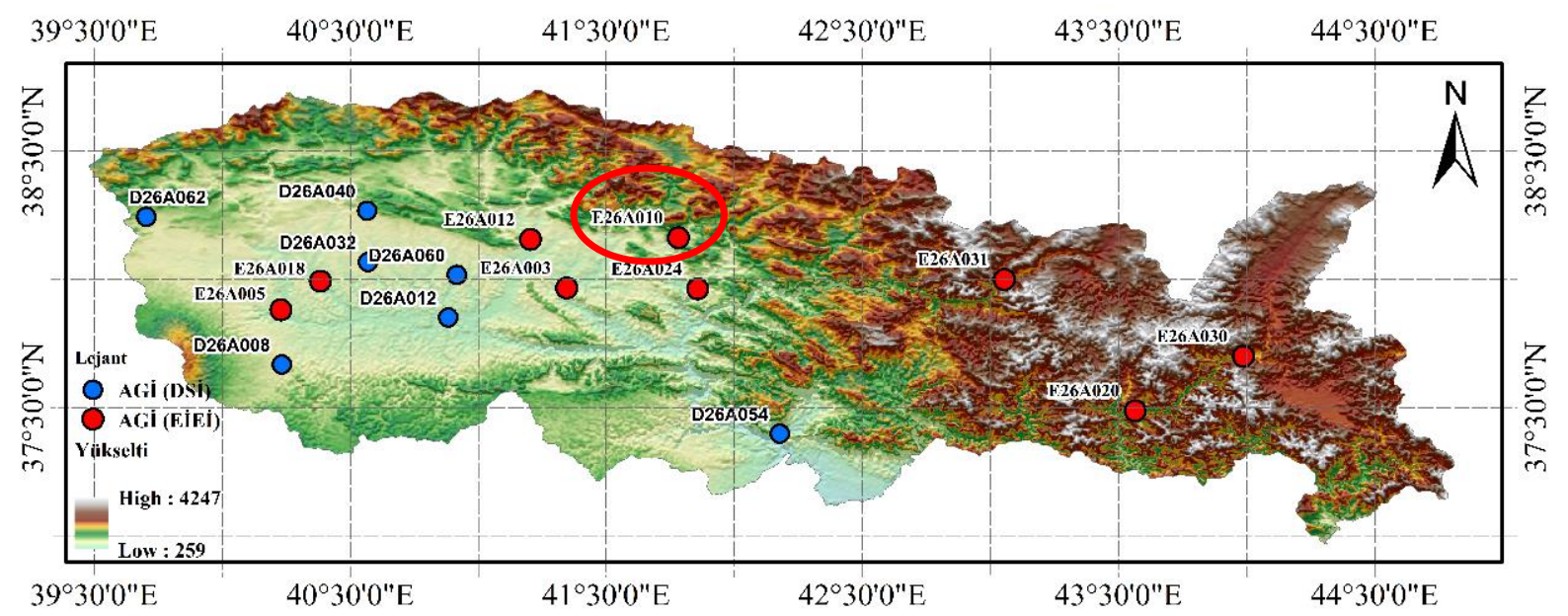

Şekil 1. Çalışma Alanı

\subsection{Akım Kuraklık İndeksi (AKI) Stremflow Drought Index (SDI)}

Nalbantis [10] tarafından geliştirilen bu yöntem ile bir çalışma bölgesindeki hidrolojik kuraklık incelenebilmektedir. Akım Kuraklık İndeksi (AKİ) aylık akım verileri $\left(\mathrm{Q}_{\mathrm{i}, \mathrm{j}}\right)$ kullanılarak hesaplanmaktadır. Burada i, hidrolojik yılı, j ise Ekim-Eylül arasındaki zaman olarak tanımlanan hidrolojik yıl içerisindeki ayı temsil etmektedir. Kümülatif akım hacmi,

$$
\begin{aligned}
V_{i, j} & =\sum_{j=3(k-1)+1}^{3 k} Q_{i, j}, k=1,2,3,4 \\
V_{i, j} & =\sum_{j=6(k-1)+1}^{6 k} Q_{i, j}, k=1,2 \\
V_{i, j} & =\sum_{j=1}^{12} Q_{i, j}
\end{aligned}
$$

Şeklinde hesaplanır. Denklem 1, 2 ve 3'te sırasıyla 3, 6 ve 12 aylık kuraklık indis değerleri hesaplanır. Denklemlerdeki k, referans periyodu ifade eder ve Denklem 1'de k=1 Ekim-Aralık (AKİ-3 Ekim), k=2 Ocak-Mart (AKİ-3 Ocak), $k=3$ Nisan-Haziran (AKİ-3 Nisan), $k=4$ ise Temmuz-Eylül (AKİ-3 Temmuz) dönemlerini temsil eder. Denklem 2'de k=1 ve k=2 sirasiyla ilk 6 ay (AKİ-6 Ekim) ve son 6 aylik (AKİ-6 Nisan) periyodları, Denklem 3 ise yıllık kuraklık indis değerini (AKİ-12) ifade eder.

Referans periyot $\mathrm{k}$ ve i'inci hidrolojik yıl için AKİ denklem 4 verildiği gibi hesaplanır.

$$
S D I_{i, k}=\frac{V_{i, k}-\bar{V}_{k}}{S_{k}}, \quad k=1,2,3,4
$$


Burada, $V_{k}$ ve $S_{k}$ sirasıyla kümülatif akım hacimlerinin ortalamasını ve standart sapmasını temsil eder. AKİ değerleri Hong, Guo, Zhou, Xiong [13] tarafından aşırı nemli ile aşırı kuraklık arasında değişen sekiz farklı sınıfta ifade edilmiştir. Bu sınıflandırma Tablo 1'de verilmiştir.

Tablo 1. AKİ değerlerinin sinıflandırması [13]

\begin{tabular}{cc}
\hline AKI Değeri & Sınıflandırma \\
\hline $\mathrm{AK} \dot{\mathrm{I}} \leq-2$ & Aşırı Kurak (AK) \\
$-2<\mathrm{AKI} \leq-1.5$ & Şiddetli Kurak (ŞK) \\
$-1.5<\mathrm{AK} \dot{\mathrm{I}} \leq-1$ & Orta Kurak (OK) \\
$-1<\mathrm{AKI} \leq 0$ & Hafif Kurak (HK) \\
$0<\mathrm{AKI} \leq 1$ & Hafif Nemli (HN) \\
$1<\mathrm{AKI} \leq 1.5$ & Orta Nemli (ON) \\
$1.5<\mathrm{AK} \dot{\mathrm{I}} \leq 2$ & Şiddetli Nemli (ŞN) \\
$\mathrm{AKI}>2$ & Aşırı Nemli (AN) \\
\hline
\end{tabular}

\section{Bulgular (Results)}

Çalışma kapsamında istasyonun aylık AKİ değerlerine göre dağılımları Şekil 2' de verilmiştir. Aylık AKİ değerlerine göre en yüksek kurak dönem \%65 ile haziran ayında gerçekleşirken, en düşük kurak dönem ise \%48 ile mart ayında meydana gelmiştir. Nemli dönemler incelendiğinde, en yüksek nemli dönem \%52 ile mart ayında gerçekleşirken en düşük nemli dönem ise \%35 ile haziran ayında hesaplanan AKİ değerleri ile elde edilmiştir. Ayrıca sadece mart ayında nemli dönem kurak dönemden fazla olmuştur. Geri kalan aylarda ise kurak dönem nemli dönemlerden fazla olmuştur. 3, 6 ve 12 aylık AKİ değerlerinin kurak/nemli dönemleri incelendiğinde ise AKİ-3 değerlerinde en yüksek kurak dönem \%52 ile AKİ-3 ekim' de gerçekleşirken, AKİ-3 ocak'ta kurak ve nemli dönem birbirine eşit olmuştur. AKİ-6 ekim ve AKİ-6 nisan dönemleri için ise kurak dönem sırasıyla $\% 50$ ve $\% 52$ olmuştur. AKİ-12' de ise kurak dönem \%48 olarak belirlenmiştir. 


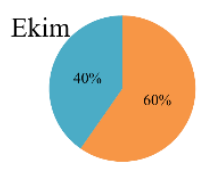

"Kurak m Nemti
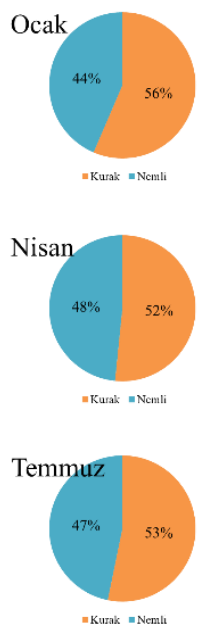

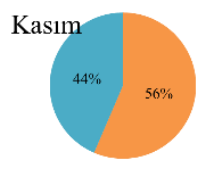

$=$ Kurahk $=$ Nemli
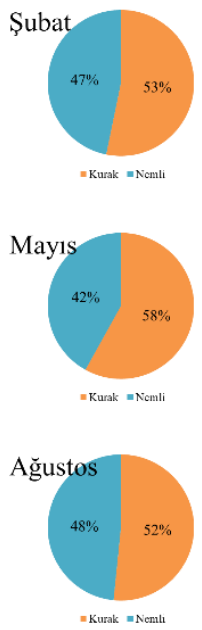

(a)
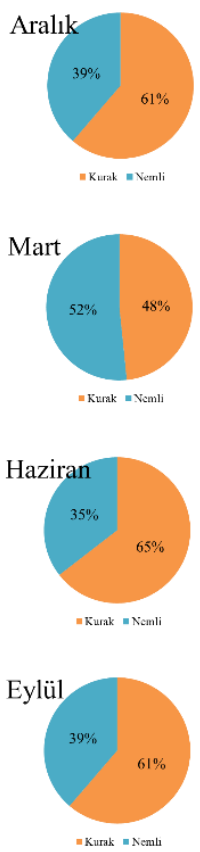
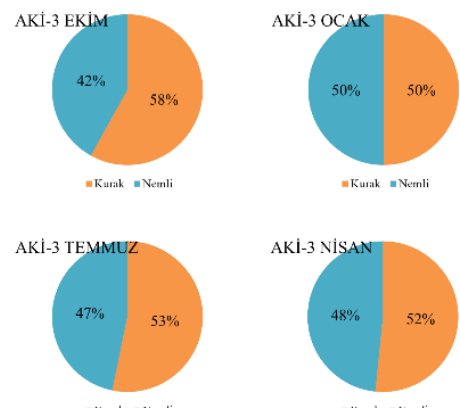

"Kurak $=$ Nemli
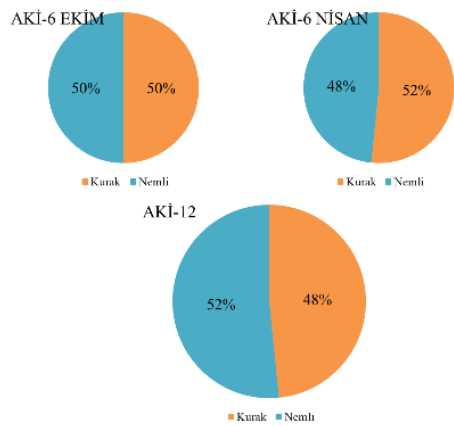

(b)

Şekil 2. AKİ değerlerinin dağılımı (a-Aylık, b-Dönemsel)

Şekil 3'te aylık Tablo 2'de verilen sınıflandırmaya göre AKİ değerlerinin kurak/nemli durumların meydana gelme yüzdeleri verilmiştir. Aylık AKİ değerlerinin oluşum yüzdeleri incelendiğinde, eylül, ekim, kasım ve aralık aylarında çok kurak ve aşırı kurak durumlara rastlanmamış, ayrıca, ocak ve şubat aylarında ise aşırı kurak durum belirlenememiştir. Bunun yanında aşırı kurak durum mart, nisan, mayıs, haziran, temmuz ve ağustos aylarında belirlenirken, en yüksek aşırı kurak oluşma yüzdesi $\% 3$ olarak nisan ve mayıs ayında belirlenmiştir.

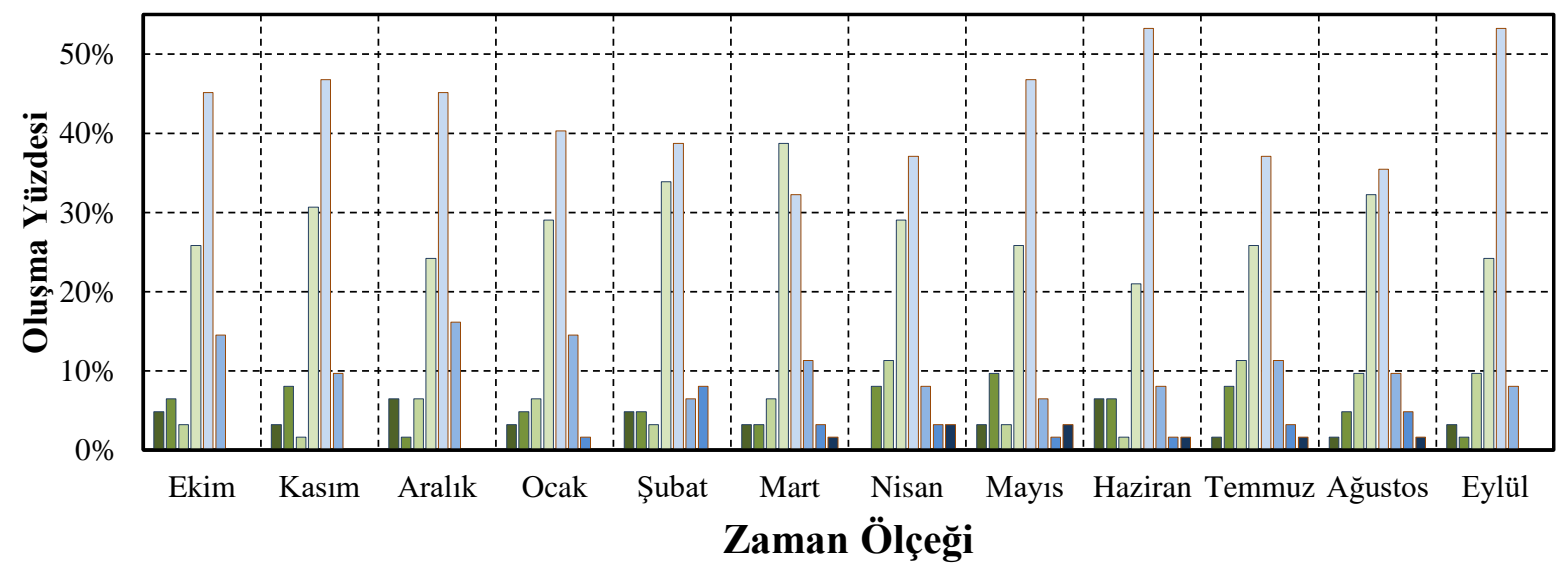

घ Aşırı Nemli $\square$ Çok Nemli $\square$ Orta Nemli $\square$ Az Nemli $\square$ Az Kurak $\square$ Orta Kurak $\square$ Çok Kurak $\square$ Aşırı Kurak

Şekil 3. E26A010 istasyonuna ait aylık AKİ değerlerinin oluşma yüzdesi 
Şekil 4'te ise 3, 6 ve 12 aylık AKİ değerlerine göre kurak/nemli durumların meydana gelme yüzdeleri verilmiştir. Buna göre, AKİ-3 nisan, AKİ-3 temmuz, AKİ-6 nisan ve AKİ-12' de aşırı kurak dönem meydana gelmiş, AKİ-3 Ekim ve AKİ-3 Ocak’ta ise aşırı kurak duruma rastlanmamıştır.

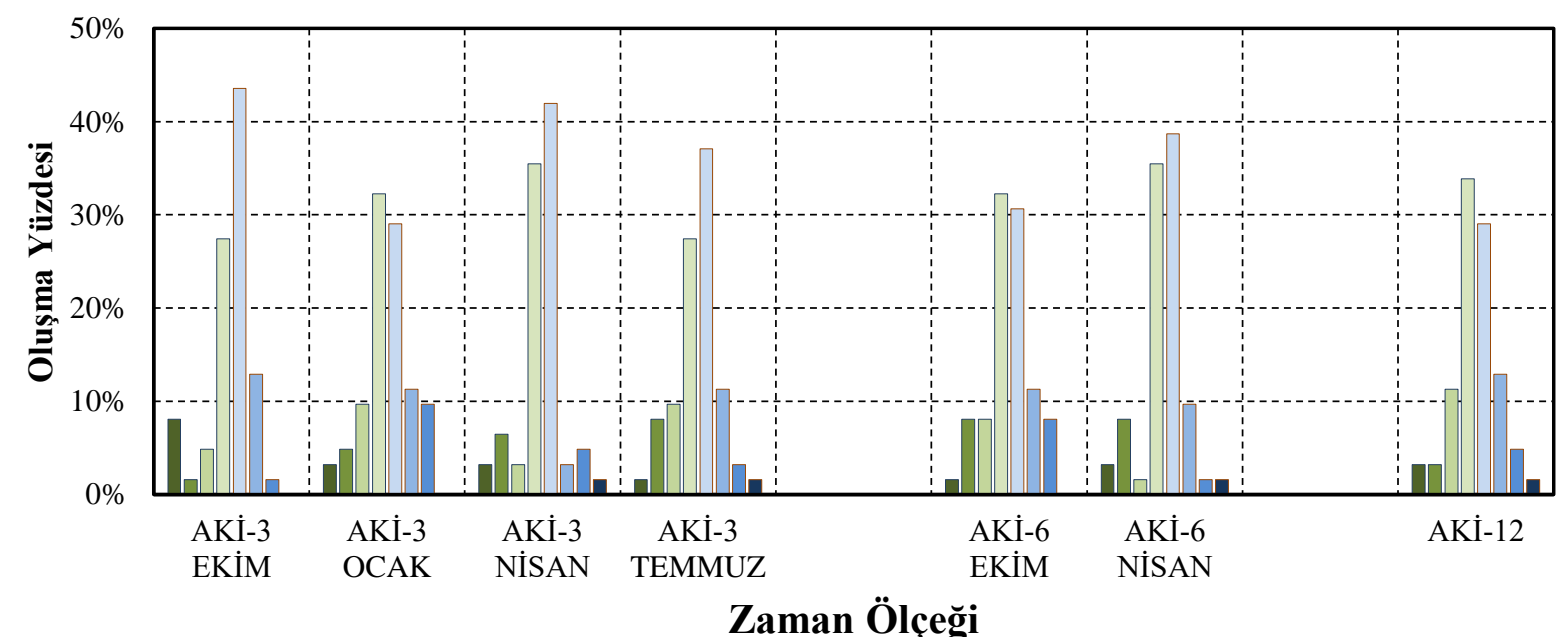

Aşırı Nemli $\square$ Çok Nemli $\square$ Orta Nemli $\square$ Az Nemli $\square$ Az Kurak $\square$ Orta Kurak $\square$ Çok Kurak $\square$ Aşırı Kurak

Şekil 4. E26A010 istasyonuna ait dönemsel AKİ değerlerinin oluşma yüzdesi

\section{Sonuçlar (Conclusions)}

E26A010 numaralı "Baykan" akım gözlem istasyonuna ait ortalama aylık akım değerleri Akım Kuraklık İndeksi (AKİ) yöntemi kullanılarak kuraklık analizi yapılmıştır. Analiz sonucunda elde edilen sonuçlar aşağıda listelenmiştir.

- Ortalama aylık akım verilerine göre en yüksek kurak dönem \%65 ile haziran ayında gerçekleşirken, en düşük kurak dönem ise $\% 48$ ile mart ayında meydana gelmiştir.

- 3, 6 ve 12 aylık AKİ değerlerinin kurak/nemli oluşma yüzdelerine göre AKİ-3 değerlerinde en yüksek kurak dönem \%52 ile AKİ-3 Ekim'de gerçekleşirken, AKİ-3 Ocak' ta kurak ve nemli dönem birbirine eşit olmuştur.

- Aylık AKİ değerlerine göre, aşırı kurak durum mart, nisan, mayıs, haziran, temmuz ve ağustos aylarında belirlenirken, en yüksek aşırı kurak oluşma yüzdesi nisan ve mayıs ayında belirlenmiştir.

- Dönemsel AKİ değerlerine göre, AKİ-3 Nisan, AKİ-3 Temmuz, AKİ-6 Nisan ve AKİ-12' de aşırı kurak dönem meydana gelmiş, AKİ-3 Ekim ve AKİ-3 Ocak’ta ise aşırı kurak duruma rastlanmamıştır.

Buna göre, canlı yaşamı üzerinden doğrudan etkili olan kuraklığın etkilerinin en aza indirgenmesi için tüm bölgenin daha fazla bir istasyonla çalışması, ayrıca zamansal kuraklıkların yanı sıra mekânsal değişimlerin de değerlendirilmesi, kuraklığın olası olumsuz etkilerini azaltmakta faydalı olacaktır. 


\section{Kaynaklar (References)}

[1] Gumus V, Algin HM. Meteorological and hydrological drought analysis of the Seyhan-Ceyhan River Basins, Turkey. Meteorol Appl 2017;24(1):62-73.

[2] Palmer WC. Meteorological drought. US Department of Commerce, Weather Bureau Washington, DC, USA; 1965.

[3] Tsakiris G, Pangalou D, Vangelis H. Regional Drought Assessment Based on the Reconnaissance Drought Index (RDI). Water Resour Manag 2006;21(5):821-33.

[4] McKee TB, Doesken NJ, Kleist J. The relationship of drought frequency and duration to time scales. Proceedings of the 8th Conference on Applied Climatology. 17. American Meteorological Society Boston, MA, USA; 1993:179-83.

[5] Bordi I, Frigio S, Parenti P, Speranza A, Sutera A. The analysis of the Standardized Precipitation Index in the Mediterranean area: large-scale patterns. Ann Geofis 2001;44(5-6):965-78.

[6] Rahmat SN, Jayasuriya N, Adnan MS, Bhuiyan M. Analysis of spatio-temporal trends using Standardised Precipitation Index (SPI). ARPN Journal of Engineering and Applied Sciences 2016;11(4):2387-92.

[7] Shah R, Bharadiya N, Manekar V. Drought Index Computation Using Standardized Precipitation Index (SPI) Method For Surat District, Gujarat. Aquatic Procedia 2015;4:1243-9.

[8] Shafer B, Dezman L. Development of a Surface Water Supply Index (SWSI) to assess the severity of drought conditions in snowpack runoff areas. Proceedings of the Western Snow Conference. 50. Colorado State University Fort Collins, CO; 1982:164-75.

[9] Weghorst K. The reclamation drought index: Guidelines and practical applications. North American Water and Environment Congress \& Destructive Water. ASCE; 1996:637-42.

[10] Nalbantis I. Evaluation of a hydrological drought index. Eur Water 2008;23(24):67-77.

[11] Tabari H, Nikbakht J, Hosseinzadeh Talaee P. Hydrological Drought Assessment in Northwestern Iran Based on Streamflow Drought Index (SDI). Water Resour Manag 2012;27(1):137-51.

[12] Tigkas D, Vangelis H, Tsakiris G. Drought and climatic change impact on streamflow in small watersheds. Science of The Total Environment 2012;440:33-41.

[13] Hong X, Guo S, Zhou Y, Xiong L. Uncertainties in assessing hydrological drought using streamflow drought index for the upper Yangtze River basin. Stochastic Environmental Research and Risk Assessment 2014;29(4):1235-47. 